\title{
Estado, Políticas Públicas e Formação Docente no Brasil: direcionamentos a partir do início do século XXI
}

\author{
Adão Aparecido Molina ${ }^{1}$ \\ Adriana Aparecida Rodrigues ${ }^{2}$
}

\begin{abstract}
RESUMO
A educação e a formação docente precisam ser compreendidas a partir de uma vertente totalizante, estabelecendo-se uma relação com a economia e a política, cuja finalidade é perceber as contradições e as ideologias presentes nas políticas educacionais em geral. Partindo desse princípio, o objetivo deste estudo é apontar o papel do Estado nas políticas públicas para a educação no Brasil a partir do inicio do século XXI, enfatizando as políticas destinadas à formação docente. Para atender tal proposto, a pesquisa se pautou em um estudo bibliográfico, por meio de uma concepção teórica pautada no materialismo histórico e dialético. Os resultados mostraram que, as políticas públicas destinadas à formação docente no Brasil estão imbricadas com a forma de organização e de administração do governo federal, consequentemente com as determinações socioeconômicas e políticas que regem as ações governamentais do país.
\end{abstract}

PALAVRAS-CHAVE: Formação Docente. Estado. Políticas educacionais.

State, Public Policies and Teaching Training in Brazil: directions from the start of the XXI century

\footnotetext{
${ }^{1}$ Pós-Doutor em História e Doutor em Educação. Professor da Universidade Estadual do Paraná - Unespar - Campus de Paranavaí, Paraná, Brasil. https://orcid.org/0000-0001-9633-4707. adaoamolina@ gmail.com.

2 Mestre em Ensino. Universidade Estadual do Paraná - Unespar Campus de Paranavaí, Paraná, Brasil. https://orcid.org/0000-0002-4694-4723.drikarodrigues66@hotmail.com.
} 


\begin{abstract}
Education and teacher training must understood be from a totalizing perspective, establishing a relationship with economics and politics, whose purpose is to perceive the contradictions and ideologies present in educational policies in general. Based on this principle, the purpose of this study is to point out the role of the State in the public policies for education in Brazil from the beginning of the 21st century, emphasizing policies aimed at teacher education. To meet this proposal, the research based was on a bibliographical study, through a theoretical foundation based on historical and dialectical materialism. The results showed that the public policies aimed at teacher education in Brazil intertwine ared with the form of administration of the federal government, consequently the economic and political determinations that govern the governmental actions of the country.
\end{abstract}

KEYWORDS: Teacher Training. State. Educational Policies.

$$
* * *
$$

\title{
Introdução
}

Neste texto discutimos sobre politicas públicas apontando que, para compreender a educação e a formação de professores é imprescindível discutir a atual forma de organização socioeconômica e política da sociedade brasileira. Todavia, é necessário, também, retomar o processo de transformações sociais, pelo qual o Brasil passou a partir da década de 1990, quando realizou os reajustes cogentes na economia, impostos pela política mundial, para a inserção na nova ordem mundial do capital.

Nessa conjuntura, consideramos que para entendermos o papel do Estado na formulação e na promulgação das políticas públicas destinadas à educação no Brasil, como as relacionadas à formação de professores no início do século XXI, temos que realizar primeiro algumas definições sobre as concepções de Estado e de política pública e social, a fim de que possamos apreender os programas e as ações do Estado nacional, dentre eles os destinados ao seguimento educacional. Também é importante realizar uma 
breve contextualização histórica sobre as reformas políticas ocorridas no final do século XX, pois os reflexos dessas reformas se perpetuam até os dias atuais.

A partir dessa afirmativa, neste estudo apresentamos o papel do Estado nas políticas públicas para a formação docente no Brasil, apontando, de forma sintetizada, uma contextualização histórica a respeito do direcionamento do Estado Nacional na formulação das políticas públicas destinas à educação e à formação docente no início do século XXI.

\section{O papel do Estado nas Políticas Públicas para a Educação no Brasil}

Compreender o papel do Estado nas políticas públicas para a educação no Brasil não é algo fácil, uma vez que o conceito de Estado parte de duas grandes vertentes: a concepção de Estado liberal e a concepção marxista de Estado na sociedade capitalista. Na concepção liberal, o Estado é compreendido como uma entidade neutra em relação à organização da vida social. Dessa perspectiva liberal, o Estado é um instrumento que atende apenas aos interesses públicos essenciais. Todavia, sob a perspectiva Marxista, que é contrária à concepção liberal de Estado, nas palavras de Vieira e Albuquerque (2001), o Estado possui uma função que não é neutra, por se configurar como uma instância que atende aos interesses da classe dominante. Mormente, as ações tomadas pelo Estado atendem aos interesses do capitalismo, não se aplicando de forma igualitária e justa. É oportuno frisarmos que concordamos com essa definição, ao argumentarmos que os desafios presentes no sistema educacional são reflexos das ações direcionadas pelo Estado para a preservação dos interesses das classes dominantes e para a reprodução do capital.

Consoante a essas ideias, Hofling (2001) afirma que, para desvendar os desafios presentes nas ações tomadas pelo Estado, temos que diferenciar primeiramente o que é Estado e governo. Segundo essa autora, o Estado é um conjunto de instituições permanentes, como exército, órgãos legislativos, dentre outros, "[...] que possibilitam a ação do governo; e Governo, como o 
conjunto de programas e projetos que parte da sociedade (políticos, técnicos, organismos da sociedade civil e outros) propõe para a sociedade como um todo [...] por um determinado período" (HOFLING, 2001, p. 31). Dessa forma, as políticas públicas são compreendidas como a ação do Estado. Consequentemente são o resultado da implementação e da manutenção do governo, sendo que, a tomada de decisões envolve diferentes agentes da sociedade e de outros organismos, bem como órgãos públicos. Fato esse que não permite que as políticas públicas sejam restringidas apenas a políticas estatais.

Sobre as políticas sociais, a autora ainda explica que elas surgiram no século XIX, a partir da instauração de movimentos sociais, marcados pelas primeiras revoluções industriais. Por se encontrarem associadas aos movimentos sociais, compreendermos que as políticas sociais visam a propiciar uma proteção social fomentada pelas determinações do Estado nacional. As políticas sociais podem ser compreendidas como ações que determinam “[...] o padrão de proteção social implementado pelo Estado, voltadas, em princípio, para a redistribuição dos benefícios sociais visando à diminuição das desigualdades estruturais produzidas pelo desenvolvimento socioeconômico" (HOFLING, 2001, p. 31). Assim, apreendemos que as ações realizadas pelo Estado para a educação, podem ser descritas como uma política pública social, que segue sob a responsabilidade do Estado, mas, também, sob a injunção de outros organismos que interferem na esfera política e na vida social em geral.

Dentro da conjuntura capitalista, o Estado é um agente regulador, que se utiliza de políticas sociais para garantir a manutenção das relações capitalistas em sua totalidade. Nesse segmento, o Estado atual cuida "[...] não só de qualificar permanentemente a mão de obra para o mercado, como também, através de tal política e programas sociais, procuraria manter sob o controle parcelas da população não inseridas no processo produtivo" (HOFLING, 2001, p. 33), ou seja, utiliza-se da própria educação para manter o controle social. Assim, compreendemos que as políticas educacionais 
podem ser definidas como instrumentos de controle social. Tendo em vista esse posicionamento, o encaminhamento da política educacional no país é determinado pelas necessidades da época em que essa política foi promulgada. Nessa ótica, a política educacional pode ser considerada uma estratégia estatal, cuja finalidade é atender as necessidades existentes na sociedade, o que, por consequência, acaba tornando-a uma política descompromissada com a formação integral e crítica dos educandos. Não obstante, a política educacional, voltada para a escola pública, serve de mecanismo controlador da sociedade, atendendo aos interesses estatais sob a ótica do capital.

Seguindo esse raciocínio, destacamos que as políticas públicas brasileiras, ao serem elaboradas, foram e são historicamente marcadas por contradições, haja vista que elas podem ser compreendidas como um instrumento de controle social ligado aos setores da produção. Essa afirmação foi constatada na investigação realizada por Oliveira e Duarte (2005) ao escreverem que, no Brasil as políticas sociais "[...] foram historicamente desenvolvidas em um contexto de muita contradição, marcado pela desigualdade no acesso e na extensão e pelo caráter fragmentário, setorial e emergencial na sua execução" (OLIVEIRA; DUARTE, 2005, p. 283).

Vale lembrar que, com o desenvolvimento do processo de industrialização, a partir de 1930, “[...] surgiu um conjunto de políticas regulamentadoras, jamais visto, porém tais políticas eram restritas a setores da classe trabalhadora urbana e industrial" (OLIVEIRA; DUARTE, 2005, p. 283), no qual os trabalhadores rurais brasileiros não possuíam os mesmos direitos adquiridos pelos trabalhadores urbanos. Em 1943, com a Consolidação das Leis do Trabalho, ocorreu uma regulamentação das relações de trabalho, proporcionando aos trabalhadores garantias no plano individual, como: direito a férias, horas-extras, entre outros. Mas foi com a Constituição Federal de 1988, que algumas políticas sociais passaram a abranger uma cobertura mais ampla, o que naquele momento representava 
um grande avanço, em decorrência da proteção social vigente. Nesse sentido, as políticas sociais desse período são destinadas ao atendimento das necessidades básicas da população.

Oliveira e Duarte (2005) registram que,

A Carta Constitucional de 1988 consolida muitas das reivindicações presentes nas pautas dos movimentos que emergem com a derrocada do regime militar. Contudo, logo após ser promulgada, tal Carta passou a ser alvo de críticas do governo Sarney (1985-1989) e dos setores mais conservadores, sendo as conquistas sociais consideradas responsáveis pela ingovernabilidade do país. [...]. O Brasil entrou nos anos de 1990 vivenciando uma era de reformas que significavam um processo de desconstrução da agenda social da Constituição de 1988, buscava desvencilhar o Estado dos compromissos sociais ali firmados, bem como um engajamento do País à nova ordem capitalista mundial, tornando-o capaz de competir na lógica do mercado livre e adotando as políticas de corte neoliberal (OLIVEIRA; DUARTE, 2005, p. 281-282).

Nessa perspectiva, a sociedade brasileira estava fundamentada na exploração e nas injustiças sociais, características essas que repercutem até os dias atuais. Diante desse contexto era preciso que ocorresse uma regulamentação social. Mas, embora essa regulação social tivesse que acontecer, ela encontrava-se ligada à ampliação de políticas sociais de cobertura universal e na regulamentação do trabalho. Para as autoras, as conquistas ressaltadas na Constituição Federal de 1988 na realidade serviram para "acalmar" a massa populacional. Algumas dessas conquistas, "[...] foram paulatinamente sendo retiradas do plano das leis, por meio de instrumentos jurídicos que exigiram, em alguns casos, até mesmo reforma constitucional, sendo que em muitas matérias a lei sequer chegou a tornarse fato" (OLIVEIRA; DUARTE, 2005, p. 285). 
Discutindo sobre essa questão, Romero (2006) aponta que, no final do século XX no Brasil, "[...] as modificações no modo de produção social, fundado no metabolismo do capital, as quais decorreram da resposta do capitalismo mundial às crises de rentabilidade e valorização que tornaram mais evidentes a partir da década de 1970" (ROMERO, 2006, p. 63-64), marcaram esse período histórico e refletiram na estruturação das políticas no país. Crises essas que abrangeram não apenas o contexto econômico, mas político, social e cultural. Diante da instauração de várias crises de cunho econômico nos "[...] principais países capitalistas industrializados a partir dos anos 70 [...], a crise da dívida dos países do Terceiro Mundo nos anos 80 e a implosão dos regimes burocráticos do Leste Europeu no fim do decênio de 1980" (TOUSSAINT, 1996, p. 235), acarretaram na propagação da ideologia neoliberal, sobre o pensamento político e econômico propagado pelo mundo, o que acarretou, também, no surgimento de movimentos sociais por parte das massas populares. A partir desse contexto, os movimentos sociais instaurados no Brasil, iniciados no final do XX, constituíram mobilizações intensas que estruturaram a política pública educacional no país.

Não obstante, nessa perspectiva de adaptações e mudanças do capital, o homem torna-se refém, de forma ideológica, do sistema econômico e político no qual está inserido, adequando-se a esse sistema sem possibilidades de questionamentos. Nessa nova ordem, o homem é tratado como mercadoria; pois, de acordo com a forma de organização vigente na sociedade, ele contribui na aquisição do capital para as classes dominantes.

Diante do exposto, entendemos que visando à superação da crise mundial de ordem econômica ${ }^{3}$, instaurou-se no país uma nova configuração

\footnotetext{
3 "No século XIX o livre mercado era um mundo imposto pela dominação inglesa. Muitos dos países hoje desenvolvidos adotaram, para crescer, políticas opostas à pregação liberal. Estados Unidos, Alemanha e Japão, por exemplo, utilizaram amplamente a intervenção estatal, o protecionismo, o apoio do poder público para implantar e fortalecer a indústria, o comércio, os transportes, o sistema bancário. Período em que estadistas e pensadores louvavam a livre concorrência como o caminho para a prosperidade, o século XIX foi também coroado por severas crises de superprodução, pânicos financeiros e pela disputa de grandes potencias na corrida para dominar impérios neocoloniais. Suas primeiras décadas foram marcadas por guerras continentais e sucessivas revoluções. Esse clima fortaleceria o tema da "rebelião das massas". Jornalistas, políticos, intelectuais, romancistas e cineastas alertavam para o perigo de um mundo que ficara permeável à presença da plebe na política. Para completar a conturbada cena, a monumental crise de 1929 daria ainda mais autoridade às saídas reguladoras que vinham sendo formuladas por liberais reformistas, adeptos da intervenção estatal, desde o início do século" (MORAES, 2001, p. 29).
} 
e uma nova dinâmica para a produção e para a acumulação do capital. Esse período é concebido, portanto, como um estágio do desenvolvimento do capital, que é marcado pelo processo de dominação, fazendo prevalecer a divisão de classes sociais na sociedade capitalista e os interesses das classes mais abastadas sobre a classe trabalhadora. Em função disso, torna-se evidente a presença de novos desafios socioeconômicos e políticos, que contribuem para a estruturação e a adequação de uma nova ordem na sociedade globalizada, desafiando todos os setores da sociedade.

A globalização pode ser conceituada como um “[...] processo de objetivação do capital. A globalização, nesse particular, radicaliza uma das mais típicas características constitutivas do capitalismo: a internacionalização, ou seja, a abertura e a integração dos mercados nacionais" (NOGUEIRA, 1997, p. 13).

Nas palavras de Nogueira (1997, p. 13), a globalização possui um duplo sentido na estruturação do Estado Nacional, pois ao mesmo tempo em que se emerge como uma nova ordem mundial causa uma desordem e uma desorganização, já que para "[...] integrar-se ao mundo, acaba abrindo [...] as portas do país para o mundo, e consequentemente acaba invadido pelo mundo". Esse segmento é decorrente das transições financeiras e comerciais, da instalação de empresas estrangeiras, de inúmeras incorporações e funções, que fazem com que o Estado perca a identidade nacional. Propagase de forma banalizadora e ilusória, como se já estivessem sido superados. $\mathrm{Na}$ verdade, isso não passa de uma estratégia, com o intuito de manter a hegemonia dominante.

Conforme os dados supracitados, podemos perceber as interferências da globalização e, especialmente, da invasão de produtos, ideias e de costumes que são importados juntos com a abertura e com uma possibilidade maior de intercâmbio entre as nações. Esses são os novos desafios enfrentados pelo estado Nacional, pago pelo preço da globalização. Ao adotar uma visão fomentada pela globalização, o Estado Nacional passa a não ter o domínio pleno de suas fronteiras e, como consequência, nem de suas ações, 
muito menos autonomia na tomada de decisões. Nessa vertente, a globalização refere-se, às relações entre as nações, sem estar compromissada com os territórios, que condicionam o funcionamento das sociedades nacionais.

A propagação da globalização, afeta as relações socioeconômicas e políticas, tornando-se um fator negativo no desempenho do Estado. Passetti (1997) afirma que, a globalização é um reflexo do neoliberalismo, que projeta a ideia da "[...] inviabilidade do capitalismo sem intervenção estatal" (PASSETTI, 1997, p. 57). O neoliberalismo se apresentou no mundo social desde o início do século XX, em decorrência de uma crise intensa na acumulação capitalista. No Brasil a onda das políticas neoliberais se propagou no final da década de 1980, e deu início às privatizações, à “[...] supressão do controle que os governos exerciam sobre as aquisições de empresas nacionais por capitais estrangeiros" (TOUSSAINT 1996, p. 61), marcadas pela grandiosa e rápida progressão de investimentos financeiros estrangeiros.

A ideologia neoliberal defende que o crescimento econômico e o desenvolvimento social do país devem ocorrer por meio de uma intervenção mínima do Estado na economia. Consequentemente, pouco a pouco, o neoliberalismo foi se apresentando como uma ideológica restauração na economia e na política mundial, a partir das ideias e das políticas que foram sendo propagadas pelos países dominantes no âmbito do capitalismo. $\mathrm{O}$ fato é que as mudanças anunciadas pelo neoliberalismo, não se configuraram de forma tão radical, a não ser pelo fim do socialismo. Firmando-se, segundo Passetti (1997), em um arranjo planetário e não em uma restauração econômica.

Como podemos constatar, a ideologia neoliberal acaba transferindo muitas regulamentações que devem ser produzidas pelos Estados, como por exemplo: regras, normas e leis, para organizações multilaterais, que procuram atender aos seus interesses socioeconômicos e políticos. Essas organizações distribuem as diretrizes políticas aos demais países 
capitalistas como meio de solução para os problemas econômicos e sociais. Nessa vertente, a economia neoliberal só beneficia as grandes potências e as empresas multinacionais. Haja vista que, os resultados das políticas neoliberais afetam negativamente os países pobres ou em desenvolvimento, uma vez que esses países possuem uma dependência financeira do capital internacional.

As inspirações neoliberais e as estratégias governamentais resultam em políticas compensatórias, marcadas pelo desenvolvimento de programas focalizados, “[...] voltados àqueles que, em função de sua 'capacidade e escolhas individuais', não usufruem do progresso social. Tais ações não têm poder - e frequentemente, não se propõem a - alterar as relações estabelecidas na sociedade" (HOFLING, 2001, p. 39).

A respeito da situação do Brasil sob a perspectiva neoliberal, no governo de Fernando Collor de Mello (1990-1992), Oliveira, Moura e Silva (2010, p. 399-400) afirmam que,

$\mathrm{O}$ então, jovem e carismático candidato alia-se a grupos de diferentes setores da sociedade, prometendo modernizar a economia, promovendo políticas de cunho neoliberal com a abertura para que empresas estrangeiras pudessem participar da economia nacional. A presidência terminou em impeachment do presidente supersônico. Foi então que o vice-presidente Itamar Franco assume para evitar uma crise maior ainda. [...]; em pouco tempo de mandato, Franco continuou com o regime de privatizações de Collor. [...]. Foi então que Fernando Henrique Cardoso tornou-se a unidade das elites para que o Brasil saísse da crise.

Como consequência dessa situação, tivemos no Brasil a instauração de crises econômicas e políticas, que afetaram principalmente a classe popular. Os interesses reguladores do mercado econômico na adoção de políticas neoliberais, por sua vez, acarretaram em ações governamentais, que direcionavam gradualmente para o afundamento do país em uma 
acentuada crise econômica. É importante frisar que, a crise econômica que se configurava no território brasileiro, naquele período, foi consequência das mudanças estruturais do capitalismo em âmbito mundial, a partir das quais houve uma difusão dos problemas econômicos que se estenderam ao longo dos anos, em território nacional. Contudo, esse cenário não se restringiu apenas ao Brasil, mas aos demais países da América Latina, que se apoiaram na ideologia neoliberal para restaurar suas economias.

Diante dessas ações de cunho econômico e político, o governo de Fernando Henrique Cardoso, que foi eleito em 1994, propôs em sua campanha eleitoral promessas destinadas à área social. Entretanto, esse governo reduziu a inflação, como forma de ponderar a desigualdade social existente no Brasil, mas cumpriu o prometido em campanha eleitoral, já que a meta era estabilizar a moeda e não realizar uma reforma de cunho social. Nesse processo em particular, “[...] as políticas sociais não fizeram senão sofrer sucessivos cortes, cada novo ajuste anunciado incluindo uma nova redução de recursos" (LESBAUPIN, 1999, p. 08), com o intuito de minimizar o déficit público. Em decorrência da adoção pela política neoliberal e pela relação subordinada a uma economia globalizada, o governo de Fernando Henrique Cardoso desenvolveu sua política econômica nos ditames do capital mundial.

A respeito da política social adotada por Fernando Henrique Cardoso, destacamos que ela pode ser considerada um desastre para a massa trabalhadora do Brasil, justamente por não assegurar os direitos sociais a toda população, mas por atender aos interesses da grande burguesia. A adoção dessa forma de governo levou a uma "sabotagem" das políticas sociais, referentes à educação, saúde, trabalho, assistência e previdência social, destinadas principalmente à massa dos trabalhadores. Essa sabotagem se valeu em cortes financeiros e "[...] manipulação de receitas, desviadas de seus fins precípuos para outras finalidades" (NETTO, 1999, p. 84, grifos do autor). 
No de Fernando Henrique Cardoso a privatização se estabeleceu no panorama brasileiro, como política estatal. "Na área social, a privatização, complementada por políticas de descentralização, fragmentação e focalização [...], constituiu-se em importante instrumento viabilizador das estratégias governamentais de coesão social" (NEVES, 2005, p. 92). O fato é que a adoção de condutas que direcionaram para a privatização, seguida de intervenções internacionais, contribuíram para a "desresponsabilização" do Estado na prestação de ações sociais, não atingindo as verdadeiras necessidades das camadas populares.

Presenciamos um paradoxo no cenário brasileiro, pois "[...] com a Constituição de 1988 houve a extensão dos direitos sociais, notadamente nas áreas da educação, saúde e seguridade social [...]. Por outro lado, com o acirramento da crise econômica e com o desmonte da estrutura de governo" (JACOBI, 1996, p. 45), se acentuou a vulnerabilidade social. Esse fato se evidencia com os altos índices de pobreza da população brasileira, pois “[...] o Brasil chegou à segunda metade da década de 90 com aproximadamente um terço de sua população em estado de pobreza e com uma completa indefinição quanto ao alcance das políticas sociais" (JACOBI, 1996, p. 45).

No governo de Luis Inácio Lula da Silva, como presidente do Brasil, ocorreu um aprofundamento do modelo democrático desenvolvido no governo FHC. No governo de Lula foi mantida "[...] a mesma política econômica monetarista de seu antecessor, e no plano político, vem tentando consolidar a formação do novo homem coletivo indispensável ao projeto de sociabilidade neoliberal [...]" (NEVES, 2005, p. 95). O discurso de Lula se configurou de forma oposta a sua forma de governo. Por pertencer a um partido político oposto ao de FHC, esperava-se uma modificação radical em sua forma de administrar o Brasil. Entretanto, deu continuidade às reformas estruturais do governo anterior. A esse respeito, Magalhães (2010) afirma que,

Contrariando as expectativas otimistas da época, o primeiro mandato do Presidente Lula não rompeu com o neoliberalismo, repetindo fielmente as linhas básicas de política econômica do seu 
antecessor, com iguais resultados em termos de baixo incremento do PIB. [...]. A preocupação com a retomada do desenvolvimento limitou-se aos repetidos anúncios do Presidente da próxima volta ao 'espetáculo do desenvolvimento' (MAGALHÃES, 2010, p. 21).

O segundo mandato de Lula da Silva foi mais incrementado, com o emprego do Plano de Aceleração do Crescimento (PAC), por meio de investimentos na infraestrutura do país. Em um aspecto geral, seguindo a visão neoliberal, seja no governo do Presidente Lula da Silva ou de seus antecessores a partir da década de 1980, ambos apresentaram um governo insatisfatório. "Apesar de certa elevação da taxa de incremento do PIB nos últimos anos do segundo mandato, ele esteve longe de relançar o Brasil na trilha do crescimento acelerado que o país registrara em longos períodos do passado” (MAGALHÃES, 2010, p. 28). Todavia, “[...] o desempenho da economia brasileira, durante o período de Lula como Presidente do Brasil, evidencia resultados gerais melhores do que o do período de $\mathrm{FHC}$ - muito especialmente quando se considera o seu segundo mandato" (FILGUEIRAS et al., 2010, p. 35).

Em relação aos aspectos sociais no governo do Presidente Lula da Silva, eles não podem ser igualados aos aspectos econômicos, pois esse presidente assegurou avanços significativos na área social, principalmente com a consolidação do programa Bolsa-Família. É importante esclarecer que, esse programa foi iniciado no governo do Presidente Fernando Henrique Cardoso, mas foi solidificado no governo do Presidente Lula da Silva. Concatenado a esse posicionamento, Sader (2013a) expõe que o governo da Presidenta Dilma Rouseff segue o mesmo perfil do traçado por Lula da Silva, sendo que ambos sofreram no desenvolvimento de seu governo as ações políticas e econômicas herdadas do governo anterior. Segundo o mesmo autor,

A década que teve fim em 2002 combinou várias formas de retrocesso. Entre elas, a prioridade do ajuste fiscal, as correspondentes quebras da economia e as cartas de intenção do 
FMI, que desembocaram na profunda e prolongada recessão que o governo Lula herdou. Na estrutura social, o desemprego, a precarização das relações de trabalho, a exclusão social e o aumento da desigualdade deram a Tônica. Já a política foi reduzida a complemento da ditadura da economia, assim como o Estado foi reduzido a Estado mínimo, com a centralidade do mercado. No plano internacional, viu-se a subordinação absoluta aos desígnios da política externa dos Estados Unidos. (SADER, 2013a, p. 07).

Tomando por base o supracitado, compreendemos que, a partir do governo de Lula da Silva, seguido de Dilma Rouseff, foram desenvolvidas ações diferenciadas do governo antecessor. Mas, essas ações aprovadas nos últimos anos, na realidade, não ultrapassaram os caminhos trilhados no governo de FHC, apenas dificultaram a propagação de alguns atos, como a violação de direitos sociais. Destacam-se os programas e ações de cunho social, assegurados a partir do governo Lula da Silva, como os referentes à garantia de renda, bens e serviços, assim como a regulação do salário mínimo. Não obstante, as políticas sociais desenvolvidas a partir do governo de Lula apresentaram uma conformação desenvolvimentista atrelada ao combate da pobreza.

Nas palavras de Sader (2013b), tanto o governo de Lula da Silva, como de Dilma Rouseff podem ser considerados como pós-neoliberais, justamente pela ruptura de elementos centrais do modelo neoliberal. Conforme o autor, esses governos apresentam características que possibilitam associá-los às categorias, como:

a) priorizam as políticas sociais e não o ajuste fiscal; b) priorizam os processos de integração regional e os intercâmbios Sul-Sul e não os tratados de livre comércio com os Estados Unidos; c) priorizam o papel do Estado como indutor do desenvolvimento econômico e da distribuição de renda, em vez de priorizar a centralidade do mercado e o Estado mínimo (SADER, 2013b, p. 138). 
No pensamento de Alves (2014), os governos de Lula da Silva e de Dilma Rouseff assumem uma postura neodesenvolvimentista, já que desde a década de 2000 temos a propagação de um novo padrão de desenvolvimento do capitalismo, o neodesenvolvimentismo. Esse autor compreende o neodesenvolvimentismo "[...] como sendo um novo padrão de desenvolvimento do capitalismo brasileiro alternativo à ortodoxia neoliberal que se constitui na década de 2000 no bojo da temporalidade histórica do capitalismo global" (ALVES, 2014, p. 51). Mas o neodesenvolvimentismo não é neoliberalismo, por se configurar como um projeto alternativo. Ainda sobre essa questão, Alves (2014) escreve que:

[...] o neodesenvolvimentismo no Brasil não é neoliberalismo, mas sim, outro padrão de desenvolvimento capitalista alternativo à ortodoxia neoliberal da década de 1990. Apesar de ter nascido da crise do modelo neoliberal no começo da década de 2000, o neodesenvolvimentismo está inserido na temporalidade histórica do capitalismo neoliberal ou bloco histórico do capitalismo flexível predominantemente financeirizado. Apesar de apresentar-se como alternativa à ortodoxia neoliberal da década de 1990, o neodesenvolvimentismo no Brasil não rompeu com a nova forma de Estado político do capital (Estado neoliberal). Pelo contrário, ele preservou o Estado neoliberal (ALVES, 2014, p. 167).

Esse delineamento aponta que o neoliberalismo foi adotado no governo do presidente Fernando Henrique Cardoso e o neodesenvolvimentismo no governo do Presidente Lula da Silva e da Presidenta Dilma Rouseff, sendo que ambos "[...], se inserem no mesmo bloco histórico: o bloco histórico do capitalismo flexível ou capitalismo neoliberal sob dominância do capital financeiro" (ALVES, 2014, p. 11). Seguindo os princípios neoliberais, o "[...] governo Fernando Henrique Cardoso se orientou pelo trinômio: abertura econômica, privatizações e desregulamentação do Estado. [...], o Estado deixou de ser o principal indutor da economia e delegou esse papel para o mercado" (ALVES, 2014, p. 
130). Já o governo de Lula da Silva, seguiu os pilares neoliberais, mas vinculado ao mercado mundial hegemônico do neoliberalismo.

A partir dessa acepção, compreendemos que ocorreu uma readequação dos padrões referentes ao desenvolvimento do capitalismo no Brasil. Nesse aspecto, o neodesenvolvimentismo ocasionou um novo cenário no mundo do trabalho, marcado pela presença de novas relações flexíveis de trabalho, já que o intuito do neodesenvolvimentismo não é eliminar o capitalismo. Ao aderir essa conduta justifica-se a propagação no país de iniciativas que buscam superar a miséria existente no Brasil, essas iniciativas devem estabelecer condições necessárias para que o indivíduo não viva em condições de miséria. É bom frisarmos que esse segmento não passa de uma estratégia que visa apenas à acumulação de riquezas, já que a miséria gera despesas e não lucro. Nesse processo em particular, temos a multiplicação de programas que visam à sociabilidade e são propostos por organizações internacionais, como a Unesco e o Banco Mundial, no intuito de subjetivamente promover os interesses e as finalidades da classe dominante.

Vale lembrar que, os programas de responsabilidade social têm “[...] o intuito de obter o consenso passivo de um contingente amplo da população ao projeto de sociabilidade burguesa e conformar mais diretamente segmentos maciços do proletariado urbano" (NEVES; SANT'ANNA, 2005, p. 37), as práticas, ideais e ideias da dominação burguesa. Como consequência, ocorre a humanização das relações sociais de apropriação, exploração e dominação na camada popular, por intermédio do trabalho e do capital. Nesse contexto de implantação de programas sociais, temos a reprodução de programas que seguem a orientação e os princípios de organizações internacionais, ligadas à ONU. A partir dessa compreensão, verificamos que a adoção de programas sociais a partir de 1990 no Brasil, está associada aos encaminhamentos internacionais, como uma estratégia para reestruturar o país. Delegam às políticas de cunhos sociais as determinações de modificarem os comportamentos humanos, em prol de assegurar o desenvolvimento econômico e a estabilidade social. 
A partir do exposto, torna-se evidente que o que ocorreu foi a implementação de um novo modelo de regulação social e não, como supostamente proposto, um investimento destinado à alteração da proteção social. A política social passou a se submeter gradualmente à política econômica, deixando uma grande camada da população sem cobertura social. Dessa maneira, podemos observar o redirecionamento do Estado em favor das políticas que foram ideologicamente disseminadas na sociedade. São essas as questões que nos ajudarão a evidenciar como foram encaminhadas as políticas para a formação docente no Brasil, a partir do final do século XX, que se propagam até os dias atuais.

\section{Educação e Formação docente no contexto socioeconômico e político brasileiro}

Analisando o sistema educacional, com relação ao exposto ao longo do estudo, evidenciamos que as tomadas de decisões nesse segmento social são decorrentes, especialmente, das ações do Estado, voltadas para as organizações nacionais e internacionais. Tais afirmações encontram respaldo nos escritos de Moraes (2009), ao registrar que as transformações no sistema educacional estão relacionadas com as modificações ocorridas no capitalismo e nas políticas públicas. Como resultado, as políticas sociais adotadas pelo Estado nacional são oriundas do desenvolvimento do capitalismo em um determinado período histórico. Nesse contexto, o sistema educacional brasileiro passou por modificações, adequando-se às intencionalidades neoliberais. A educação, na perspectiva neoliberal, passou a ser visualizada como um elemento provedor de superação da crise econômica que se instaurava pelo país, bem como em outros países considerados em desenvolvimento, como os pertencentes à América Latina e ao Caribe.

A partir da década de 1990 ocorreu uma reestruturação na organização educacional no Brasil. Nesse período, as reformas e a 
elaboração de programas educacionais estavam pautadas nos novos modelos de produção, que são marcados pela apropriação de condutas que valorizam a autonomia, a polivalência e a flexibilidade. Dessa forma, a reforma educacional ocorrida a partir desse período pode ser descrita como uma estratégia de adaptação, visando a adequar o homem às exigências do modelo capitalista em curso. Por conseguinte, o sistema educacional passou a apresentar determinações que visassem à formação desse novo modelo de homem, demonstrando que esse ajustamento foi pensado e delineado, em especial, pela interferência das organizações internacionais.

Nesse período, ocorreu a utilização da aparelhagem escolar, bem como dos instrumentos educacionais do cotidiano social como forma de intervenção do Estado no desenvolvimento do panorama educacional brasileiro. Essa intervenção "rápida" está relacionada ao enfoque de formar um indivíduo que atenda ao novo padrão social, o que, por consequência, exigiu modificações no sistema educacional brasileiro. Sobre essa questão, Neves (1999) aponta que,

A educação escolar no Brasil, no Governo FHC, consolida a tendência já evidenciada nos governos Collor e Itamar Franco de responder aos imperativos da associação submissa do país ao processo de globalização neoliberal em curso no mundo capitalista, ou seja, o sistema educacional como um todo redefine-se para formar um novo trabalhador e um novo homem que contribua para a superação da atual crise internacional capitalista. A educação brasileira, portanto, se direciona organicamente para efetivar a subordinação da escola aos interesses empresariais na 'pósmodernidade' (NEVES, 1999, p. 134, grifos do autor).

Já no segundo mandado do presidente Fernando Henrique Cardoso, mantiveram-se as ações destinadas ao Ensino Fundamental, no qual se destacou nesse período a ampliação "[...] em Programas Municipais de Garantia de Renda Mínima, com a criação do Bolsa-Escola para parcela do alunado do Ensino Fundamental, em 2001" (OLIVEIRA; FERREIRA, 2008, 
p. 38). Essas reformas foram seguidas também no governo do Presidente Lula da Silva. Com a eleição de Lula da Silva almejava-se que ocorreriam modificações mais efetivas e/ou significativas no processo educacional. As ações políticas destinadas à educação brasileira, foram prioritárias nesse governo, em programas como: Brasil Alfabetizado e a criação do Fundo de Manutenção e Desenvolvimento da Educação Básica (FUNDEB).

Neves (2005) justifica que, no caso do programa Brasil Alfabetizado, ocorreu um aumento na bolsa financiada pelo Estado, mas os frequentadores do programa são candidatos a se tornarem analfabetos funcionais. Em relação ao FUNDEB, ela explica que o programa não melhorou de fato a qualidade da educação fundamental e no que diz respeito à reforma da educação superior, ela está relacionada com as diretrizes preconizadas por organizações internacionais, reforçando, ainda mais, a precarização da relação trabalho e ensino, além de propiciar uma conformação cívica. $\mathrm{Na}$ interpretação de Leher (2010), “Analisar a política educacional de um determinado governo é uma tarefa complexa. As tentações provocadas por cantos de sereia e pelas paixões são poderosas" (LEHER, 2010, p. 370). Mas diante das modificações na forma de governo, apontamos que o Governo de Lula e de Dilma seguiram as primícias sancionadas no governo anterior, ou seja, não ocorreu um rompimento definitivo com a forma administrativa que estava em curso.

A partir desses levantamentos enfatizamos que, as políticas públicas aprovadas no Brasil a partir do final do século XX, não atendem à realidade do país, mas atendem às determinações internacionais, que por sua vez, acatam os interesses do capital. Destacamos que, as modificações que ocorreram nesse período surgiram diante da pretensão que o Brasil possuía em integrar-se ao mundo globalizado, justamente por fazer parte dos países em desenvolvimento e com problemas de ordem social, econômica e política. Como consequência dessa interação globalizadora, no Brasil foram elaborados e desenvolvidos projetos para solucionar problemas relacionados às questões educacionais, como o analfabetismo e, também, foram firmados 
acordos para melhorar a educação básica, com a qual a formação de professores está relacionada, justamente pelo fato de que o ensino nas escolas de educação básica prescinde de uma formação docente de qualidade nas universidades, que preparam e capacitam os futuros professores para o exercício da difícil tarefa de ensinar, transmitindo o conhecimento científico aos educandos.

Com a aprovação de legislações que orientam a educação, a partir do final do século XX, relacionadas à política internacional, a formação do professor nesse período apoia-se na vertente de qualificação para o mercado de trabalho. Os professores precisam de qualificação para atender às necessidades sociais que estão postas nas relações de produção e de reprodução da vida material humana. A posição adotada pelos representantes governamentais do Brasil, a partir de 1990, se configurou com as orientações das políticas internacionais, mesmo tendo ocorrido grandes avanços no contexto educacional, com a promulgação da Constituição Federal de 1988, que definiu diretrizes legais para o contexto educacional e com a aprovação da Lei de Diretrizes e Bases (LDB) nº. 9.394 de 1996. Sobre esse assunto, Gomide (2010) salienta que, no caso da Constituição Federal de 1988, a obrigatoriedade da educação limita-se ao ensino fundamental, seguindo as orientações internacionais. A LDB n. ${ }^{\circ}$ 9.394 de 1996, com as ações descentralizadoras, responsabilizaram o município em proporcionar a educação infantil e o ensino fundamental séries iniciais e os estados em assegurar o ensino fundamental séries finais e a ofertar o ensino médio.

A instauração de modificações no sistema educacional teve como consequência a necessidade de mudanças nas políticas destinas à formação de professores. Dentre as alterações ocorridas temos como propostas: modificações no currículo de formação docente; utilização de tecnologias e flexibilidade na metodologia; incentivos destinados à privatização da formação, bem como o segmento dos interesses presentes no "[...] mercado da educação, a diminuição do tempo e da qualidade epistemológica dos 
conteúdos, em prejuízo à formação de educadores que têm a docência como base e é desenvolvida de modo articulado à base comum nacional" (GOMIDE, 2010, p. 114). Nesse sentido, as alterações destinadas à formação de professores ocorreram a fim de adequá-los à nova demanda do profissional exigida pelo mercado de trabalho.

É relevante registrar que, a LDB de 1996 assegura o proposto na Constituição Federal de 1988, no artigo 205, no que se refere ao preparo do indivíduo, por meio da educação, a uma qualificação para o trabalho. De fato, temos atualmente no Brasil a expansão de cursos técnicos, cujo intuito é formar mão de obra para o mercado de trabalho. Com a mudança na reformulação do sistema educacional, a educação escolar assumiu uma postura de preparar o indivíduo para atender às demandas do mercado de trabalho. Todavia, não podemos generalizar, já que a educação pode ser utilizada como um instrumento de compreensão do funcionamento da sociedade, desde que seja transmitida a partir de uma visão crítica e reflexiva.

Contudo, a mudança nas políticas destinadas a professores não se restringem apenas a esse profissional, mas deve acontecer em conformidade com as transformações nas demais políticas referentes à escola, ao currículo, à gestão e à administração escolar. Seguindo essa lógica, o educador se tornou flexível, correspondendo às exigências do mercado de trabalho. Nessa perspectiva, não são levados em consideração os desafios preconizados pela falta de consonância da gestão e de sua proposta pedagógica, o que implicará em "[...] aceitar as críticas que têm sido orquestradas pelo neoliberalismo, que são 'acadêmicas' significando rígidas sem ser rigorosas, pouco ágeis para atender às novas demandas, tradicionais e pouco competentes" (KUENZER, 1998, p. 09).

É importante esclarecer que, a formação de professores segue as determinações legais fomentadas pelo país. Ao delegarem-se aos professores os desafios para a constituição de uma educação básica de qualidade, tem-se por consequência, uma relação que se configura de forma contraditória; pois 
se os ensinamentos dos professores não são de qualidade para propiciar uma qualidade efetiva na educação, porque não promulgar políticas que visem à qualidade também na formação docente. A resposta é muito clara, o intuito não é obter qualidade, mas manter uma quantidade de alunos nos estabelecimentos escolares, para atender às necessidades sociais.

Nesse processo em particular, Saviani (2011) argumenta que, o problema se coaduna com a historicidade da formação docente, marcada pela presença ou não de procedimentos pedagógico-didáticos, que se modificaram diante das transformações socioeconômicas, políticas e culturais do país. Desde as reformas instauradas no país no final do século $\mathrm{XX}$ aos dias atuais, temos a permanência de políticas formativas marcadas pela precariedade "[...] cujas sucessivas mudanças não lograram estabelecer um padrão minimamente consistente de preparação docente para fazer face aos problemas enfrentados pela educação escolar em nosso país” (SAVIANI, 2011, p. 10).

Tal problemática está associada ao fato de que a formação docente está voltada para os interesses sociais da classe dominante. A formação de professores presa aos interesses e às intencionalidades sociais dos trabalhadores não pode ser embasada apenas em uma formação técnica, marcada pelo desenvolvimento de competências práticas, mas deve decorrer de uma ampliação científica dessa formação. Essa ampliação na formação docente deve ser promovida, a fim de que os professores possam realizar as novas tarefas e superar os desafios relacionados, em especial com a atualização constante.

Nas palavras de Kuenzer (1999), “[...] as demandas de formação de professores respondem às configurações que se originam nas mudanças ocorridas no mundo do trabalho e nas relações sociais" (KUENZER, 1999, p. 166), sendo que as políticas destinadas ao sistema educacional são marcadas pelos interesses e finalidades contraditórias que emergem no encadeamento de forças na busca pelo poder. Nesse cenário, não basta para o professor ser detentor de conteúdos específicos de sua área de atuação, sendo que o 
mesmo deve se capacitado para "[...] conhecer os modos como se dá a aprendizagem em cada etapa do desenvolvimento humano, as formas de organizar o processo de aprendizagem e os procedimentos metodológicos próprios a cada conteúdo" (KUENZER, 1999, p. 172).

Lembramos que, segundo as diretrizes atuais, a formação de professores, em especial no ensino superior, nos cursos de licenciaturas é destinada à formação docente para a educação básica. Nessa perspectiva, "[...] no Brasil, quando se trata de formação de professores, na maioria das vezes faz-se referência aos níveis de ensino da educação básica: educação infantil, ensino fundamental e médio, excluindo o ensino superior" (BATISTA, 2011, p. 02). Essa indefinição é resultado da falta de uma formação suficiente e adequada que fundamente o desenvolvimento do trabalho cotidiano do professor no ensino superior. Tendo em vista essas afirmações, torna-se evidente a necessidade do desenvolvimento de uma política destinada à formação de professores, que valorize esse profissional, articulando sua formação inicial, continuada e as condições de trabalho, de forma qualitativa. A adoção de uma política que abranja esses segmentos e orientações implica em modificações no sistema educacional como um todo. Fato esse que, atualmente é considerado utópico, diante da conjuntura e dos interesses que existem por trás das promulgações legais, sobretudo no campo educacional.

\section{Conclusão}

Diante do exposto ao longo do estudo, que discutiu o papel do Estado na promulgação de políticas educacionais e, em especial, as destinadas à formação de professores no Brasil no início do século XXI, evidencia-se que a formação docente está relacionada com as condições que estão postas no contexto socioeconômico, e interligadas às necessidades e aos interesses do capital no período estudado. Consequentemente, a prática cotidiana do 
professor, nos estabelecimentos de ensino, reflete a conjuntura social na qual esse profissional se insere.

Observamos que o Estado se utiliza da promulgação de políticas públicas de cunho social para naturalizar suas ações perante a massa popular. O fato é o exposto na legislação não atende à realidade do país, justamente porque as ações tomadas pelo Estado estão associadas aos interesses e às determinações das organizações internacionais. Vale destacar que, a redefinição do papel do Estado, que ocorreu no final do século XX no Brasil, afetou a política educacional no período posterior. As reformas necessárias, disseminadas pelo neoliberalismo, pregavam que o Estado precisava de mudanças por se encontrar em crise, mas, no entanto, a crise que se instaurava era no sistema capitalista. Nessa direção, o que prevaleceu foram as reformas econômicas e políticas para manter os interesses capitalistas sobre o sistema educacional.

A partir das mudanças ocorridas no papel do Estado, diante do contexto neoliberal, as instituições de ensino passaram a ser consideradas improdutivas, segundo a lógica de mercado, necessitando, portanto, de intervenções. Ainda, sobre essa questão, é possível perceber que a partir dos anos 1990 foram desenvolvidas algumas iniciativas com a finalidade de reformar o sistema educacional público. Mas, na realidade essas ações objetivavam atender à demanda existente no mercado de trabalho.

Todavia, as modificações não se restringiram exclusivamente aos conteúdos a serem ensinados, mas, também, às políticas que orientam o sistema educacional, como as ligadas às formas de gestão, de controle e de financiamento da educação. Por conseguinte, foi e é delegada à educação uma mobilidade social, na qual ela é considerada a solução dos problemas do país, em especial os de ordem econômica. Na realidade, o sistema capitalista faz uso de um aparato ideológico bem eficaz, a partir do qual desenvolve no imaginário da classe dominada a ideia de que todos obterão os mesmos privilégios da classe dominante. Dessa forma, a intervenção internacional, juntamente com as ações do governo nacional, é ideologicamente disfarçada 
e, na verdade, mascara a essência das questões sociais, aumentado as desigualdades sociais.

Consideramos que, as amarras sociais estão presentes nos discursos divulgados na sociedade, visando a solucionar as problemáticas em torno do sistema educacional e da formação de professores. Nesse sentido, as modificações que visem a qualificar a formação docente devem partir de mudanças que atinjam a formação e o desenvolvimento do trabalho cotidiano do professor. Contudo, as modificações no processo formativo docente são um desafio a ser superado, justamente por essas transformações se firmarem inicialmente no processo de trabalho e não propriamente no sistema educacional. Todavia, os desafios encontrados para a efetivação de uma formação docente de qualidade estão relacionados ao contexto social no momento da elaboração e da aprovação dos documentos legais, que são decorrentes das reformas econômicas e políticas nos anos 1990 e das pressões e recomendações das organizações internacionais. Não obstante, falar em política educacional para a formação de professores, a partir do início do século XXI, isto é, a partir do ano 2000, é falar em desafios, em contradições de caminhos ou de orientações que atendam às necessidades reais e que possam ser seguidas nas instituições que promovem a formação desses profissionais para o ensino na educação básica.

\section{Referências}

ALVES, Giovanni. Trabalho e neodesenvolvimentismo: choque de capitalismo e nova degradação do trabalho no Brasil. Bauru: Canal 6, 2014.

BATISTA, Elaine Regina Martins. Políticas de formação para o professor do ensino superior. In: Reunião Anual da ANPED, 34, 2011. Natal, RN. Anais... Disponível em:<http://www.anped.org.br/simposio2011/PDFs/trabalhoscompletos/comunicacoe srelatos/0160.pdf>. Acesso em: 27 jan. 2014.

FILGUEIRAS, Luiz et al. Modelo liberal-periférico e bloco de poder: política e dinâmica macroeconômica nos governos Lula. In: MAGALHÃES, João Paulo de Almeida et al (Org.). Os anos Lula: contribuições para um balanço crítico 20032010. Rio de Janeiro: Garamond, 2010. p. 35-69. 
GOMIDE, Angela Galizzi Vieira. Políticas da UNESCO para formação de professores no Brasil: uma leitura da desqualificação da educação brasileira. Caderno de Pesquisa: pensamento educacional, Curitiba, v. 05, n. 11, p. 107-126, set./dez., 2010. Disponível em:

$<$ http://www.utp.br/cadernos_de_pesquisa/pdfs/cad_pesq11/7_politicas_da_unesco_c p11.pdf $>$. Acesso em: 22 set. 2014.

HOFLING, Eloísa de Mattos. Estado e políticas (públicas) sociais. Cad. CEDES, v. 21, n. 55, p. 30-41, nov. 2001. Disponível em: <http://dx.doi.org/10.1590/S0101$32622001000300003>$. Acesso em: 30 jan. 2014.

JACOBI, Pedro. Transformações do estado contemporâneo e educação. In: BRUNO, Lúcia (Org.). Educação e trabalho no capitalismo contemporâneo. São Paulo: Atlas, 1996. p. 41-56.

KUENZER, Acácia Zeneida. As políticas de formação: a constituição da identidade do professor sobrante. Educação \& Sociedade, Campinas, v. 20, n. 68, p. 163-183, dez. 1999. Disponível em: <http://www.scielo.br/pdf/es/v20n68/a09v2068.pdf>. Acesso em: 28 mar. 2014.

LEHER, Roberto. Educação no governo de Lula da Silva: a ruptura que não aconteceu. In: MAGALHÂES, João Paulo de Almeida et al (Org.). Os anos Lula: contribuições para um balanço crítico 2003-2010. Rio de Janeiro: Garamond, 2010. p. $369-412$.

LESBAUPIN, Ivo. Apresentação: o desmonte de um país. In: LESBAUPIN, Ivo (Org.). O desmonte da nação: balanço do governo FHC. 3. ed. Petrópolis, RJ: Vozes, 1999. p. 07-13.

MAGALHÃES, João Paulo de Almeida. Estratégias e modelos de desenvolvimento. In: MAGALHÃES, João Paulo de Almeida et al. (Org.). Os anos Lula: contribuições para um balanço crítico 2003-2010. Rio de Janeiro: Garamond, 2010. p. 19-34.

MORAES, Reginaldo. Neoliberalismo: de onde vem, para onde vai? São Paulo: SENAC, 2001.

MORAES, Salete Campos. (Re) Discutindo a ação do estado na formulação e implementação das políticas educacionais. Educação, Porto Alegre, v. 32, n. 03, p. 159-154, maio/ago. 2009. Disponível em: <revistaseletronicas.pucrs.br/ojs/ index. $\mathrm{php} /$ faced/article/download/.../4011>. Acesso em 30 jan. 2014.

NETTO, José Paulo. FHC e a política social: um desastre para as massas trabalhadoras. In: LESBAUPIN, Ivo (Org.). O desmonte da nação: balanço do governo FHC. 3. ed. Petrópolis, RJ: Vozes, 1999. p. 75-89.

NEVES, Lúcia Maria Wanderley. Educação: um caminhar para o mesmo lugar. In: LESBAUPIN, Ivo (Org.). O desmonte da nação: balanço do governo FHC. 3. ed. Petrópolis, RJ: Vozes, 1999. p. 133-152. 
NEVES, Lúcia Maria Wanderley. A sociedade civil como espaço estratégico de difusão da nova pedagogia da hegemonia. In: (Org.). A nova pedagogia da hegemonia: estratégias do capital para educar o consenso. São Paulo: Xamã, 2005. p. $85-125$.

NEVES, Lúcia Maria Wanderley; SANT'ANNA, Ronaldo. Introdução: Gramsci, o Estado educador e a nova pedagogia da hegemonia. In: NEVES, Lúcia Maria Wanderley (Org.). A nova pedagogia da hegemonia: estratégias do capital para educar o consenso. São Paulo: Xamã, 2005. p.19-39.

NOGUEIRA, Marco Aurélio. A dimensão política da descentralização participativa. São Paulo em Perspectiva, v. 11, n. 03, p. 08-19, São Paulo, 1997.

OLIVEIRA, Caroline Mari; MOURA, Kethlen Leite; SILVA, Irizelda Martins de Souza e. Relatório Delors e Relatório Cuéllar: desmitificando a diversidade cultural e a educação na política educacional brasileira a partir da década de 1990. Visão Global, Joaçaba, v. 13, n. 02, jun./dez., p. 397-418, 2010. Disponível em: $<$ http://editora.unoesc.edu.br/index.php/visaoglobal/article/view/967>. Acesso em: 30 jan. 2014.

OLIVEIRA, Dalila Andrade; DUARTE, Adriana. Política educacional como política social: uma nova regulação da pobreza. Perspectiva, Florianópolis, RJ, v. 23, n. 02 , p. 279-301, jul./dez. 2005. Disponível em: <http://www.ced.ufsc.br/nucleos/nup/ perspectiva.html>. Acesso em: 16 set. 2014.

OLIVEIRA, Dalila Andrade; FERREIRA, Elisa Bartolozzi. Políticas sociais e democratização da educação: novas fronteiras entre público e privado. In: AZEVEDO, Mário Luiz Neves (Org.). Políticas públicas e educação: debates contemporâneos. Maringá: EDUEM, 2008. p. 23-46.

PASSETTI, Edson. Governamentalização do estado e democracia midiática. São Paulo: 1997. p. 55-64.

ROMERO, Ana Paula Hamerski. Análise da política pública brasileira para a educação especial na década de 1990: configuração do atendimento e atuação do terceiro setor. 2006. 220 f. Dissertação (Mestrado em Educação) - Universidade Estadual de Maringá, Maringá, 2006.

SADER, Emir. Apresentação. In: SADER, Emir (Org.). 10 anos de governos pósneoliberais no Brasil: Lula e Dilma. São Paulo, SP: Boitempo; Rio de Janeiro: FLACSO Brasil, 2013a. p. 07-08.

A construção da hegemonia pós-neoliberal. In: SADER, Emir (Org.). 10 anos de governos pós-neoliberais no Brasil: Lula e Dilma. São Paulo, SP: Boitempo; Rio de Janeiro: FLACSO Brasil, 2013b. p. 135-143.

SAVIANI, Dermeval. Formação de professores no Brasil: Dilemas e perspectivas. Revista Pedagógica, v. 09 n. 01, jan./jun. 2011. Disponível em: <www.revistas.ufg.br/index.php/poiesis/article/view/15667/9592>. Acesso em: 10 jun. 2013. 
TOUSSAINT, Eric. A bolsa ou a vida: a dívida externa do terceiro mundo: as finanças contra os povos. Brasília: Fundação Perseu Abramo, 1996.

VIEIRA, Sofia Lerche; ALBUQUERQUE, Maria Glácia Menezes. Política $e$ planejamento educacional. 2. ed. Fortaleza: Demócrito Rocha, 2001.

Recebido em abril de 2019.

Aprovado em novembro de 2019. 